\title{
Manuel Acensio Segura y "La Peli-Muertada"
}

\section{Por Alberto tauno}

Virtualmente inédita puede considerarse La Pell-Muertada, pues sólo vió la luz pública en El Moscón, periódico muy circunstancial y volandero, que Manuel Ascensio Segura editó en Piura, entre 1848 y 1851, para repeler las intrigas que en su perjuicio urdía un inescrupuloso aspirante al empleo que allí desempeñaba el poeta; y en un folleto, cuyos pliegos se hicieron quizá con las formas tipográficas del periódico, cuya portada parece no haber sido impresa porque se aguardaba completar previamente el texto, y que, por tanto, no debió circular jamás.

En 1885 incluyól Ricardo Palma algunos fragmentos del poema, en la compilación de Iosc Artículos, poesías $y_{n}$ comedias de Manuel Ascensio Segura, "para dar al lector idea del personalísimo trabajo en que [éste] malgastó su rica vena poética". Y, en verdad, no es posible dilucidar el criterio que el eminente tradicionista siguió, pues de una parte juzga La Peli-Muertada como original expresión de una "rica vena poética", y halla en sus versos "chiste, travesura de ingenio y aquella difícil facilidad de que nos habla Moratín"; y de otra, recorta su texto en forma que desdice el propósito de ofrecer las "obras completas" del celebrado costumbrista. Quizá deba establecerse que el tradicionista, retirado ya de la política y asqueado de sus menudas pugnas, aplicó alguna reserva sentimental a la lectura y la estimación del poema; y, por eso, luego de elogiar su forma, censura "la pasión" vertida en él y anuncia que sólo trascribirá los tragmentos "menos ofensivos". E inclusive explicaríanse así los gruesos errores que desliza en su noción de La Peli-Muertada : dividida sólo en dieciseis cantos, y no en "veinticuatro"; con 2197 versos, notablemente disminuídos en 
cuanto afirma que son "más de mil doscientos"; en octosílabos, que apenas se interrumpen para dar cabida a una breve interpolación, y no "en variedad de metros". No obstante, este poema satírico ha sido conocido durante varias décadas a través de los mencionados fragmentos, y calificado en términos muy aproximados a los suscritos por el eminente tradicionista.

Por suerte, el señor José del Carmen Ramos conserva, en Piura, un ejemplar del folleto, cuya impresión quedó inconclusa en 1851. Cuidadosamente lo hizo copiar el doctor Gonzalo Carbajal y Segura, nieto del poeta, a quien visitamos el año 1947 -para conocer su notable colección de ediciones de El Quijote-, y hubimos de agradecerle la señalada gentileza de poner el texto a nuestra disposición, permitiéndonos rastrear la huella del oscuro personaje que en sus versos perpetuó el ingenioso costumbrista. $Y$ supimos que también había proporcionado la copia a Luis Alberto Sánchez, que a la sazón preparaba su ensayo crítico y biográfico sobre El señor Segura, hombre de leatro, en cuyas páginas corren parejas una integral visión del poema y una interpretación inexacta del destino que su autor le diera.

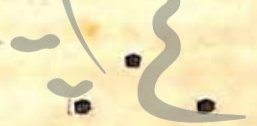

La Pell-Muertada es un poema satiricoetenderezado contra un aventurero mulato "que a través de los yaivenes del caudillismo militar disfrutó desaprensivamente de los favores que algunos poderosos quisieron otorgarle; $\mathrm{y}$, hostigado por su presunción y sus pujos de notoriedad, cubrió un día sus delatores rizos con una peluca lacia y rubia, a la cual debió el burlesco apelativo que inmediatamente le fué aplicado. En la prensa y en las murmuraciones callejeras fué señalado con el mote de "Peli-Muerto", que equivale a decir "pelo de muerto" o "pelo muerto". Y no fué pura humorada, ni casualidad, el hecho de que Manuel Ascensio Segura llamara "epopeya de última moda" a la obra en la cual debía cantar la palinodia de tal personaje, pues era un hombre honesto, que solía llamar a las cosas por su nombre justo y aplicaba las palabras en su acepción cabal. Su estilo es directo y elocuente, objetivo y preciso; no frecuenta la metáfora, ni la hipérbole; $y$, cuando admite la ironía, es en forma tan rotunda que impone la deducción moralizadora. De manera que hallamos una definición y una calificación plenas en ese término: "epopeya de última moda". 
Lo primero, en atención a la forma genérica más adaptable al propósito de "narrar... la vida, milagros y conocidas proezas del famoso Peli-Muerto"; y lo segundo, porque éste no lucía los contornos generosos de los héroes cuyos hechos llenaron las epopeyas clásicas y era, apenas, "una prenda de nuestra civil contienda", intrigante y veleidoso, simulador y rapaz. Si la acción y el protagonista carecían de grandeza la epopeya que los cantare no podía imitar un arquetipo; y, extremando el contraste, ciñóla el autor a la "última moda", para franquear así las convenciones formales y acogerse a una total libertad de creación. Pero no se requiere mucha agudeza para advertir que esa calificación de su obra ha apuntado simultáneamente hacia dos objetivos, pues expresa una tácita censura del estado político y social a cuya sombra podía medrar un personaje como Peli-Muerto, e insinúa una adversa crítica a las pujantes innovaciones del romanticismo. Por tanto, será fácil comprobar que la actitud vital de Manuel Ascensio Segura se trasluce en la sátira con mayor nitidez que en sus comedias : adicto a un liberalismo ordenado, en el cual no quepan los atropellos ni las improvisaciones, sino el equilibrado juego de aptitudes y valores éticos; y opuesto a la afectación y los desbordamientos verbales, en cuanto pueden óscurecer la veracidad del pensamiento y alterar la dignidad del estilo.

Ostentosamente niega Manuel Ascensio Segura la validez de los preceptos retóricos, en cuanto afecta acogerse a las libertades poéticas del romanticismocyinconisagra uños despectiva mención a ciertos retores famosos:

¿Quién de Hugo Blair ni de Horacio escucha ya los consejos? Vayan a un cuerno esos viejos con sus caras de topacio.

Y Moliére, y Moratín, que con Boileau y La Rosa bailaban la mariposa y jugaban al pimpín.

$Y$ Cienfuegos y Pincianos,

140 Luyandos y Gorostizas, que comían longanizas y se lavaban las manos. 
Basta ya de tiranía :

145 rienda suelta al pensamiento, háblese así de un convento como de una pulpería.

Pero aquella es sólo una declaración verbal, que no se halla confirmada en la modelación de la Peli-Muertada, pues el plan y las formas métricas se ajustan a las viejas normas. Y por eso estimamos que, implícitamente, ha expresado la creencia de que rebaja la poesía quien emplea su divino lenguaje en temas tan vulgares como los entuertos de un pícaro. Oculta una sarcástica sonrisa al insinuar que la libertad del romanticismo permite buscar héroes en las pulperías y aún tolerar absurdos. Piensa que un siglo antes se habría condenado o exorcizado a los románticos en un solemne auto de fé, y opone la madura reflexión del clasicismo a la precipitación de la nueva escuela:

175

Yo que ni al clásico sigo ni al romántico tampoco, unas veces me desboco $\mathrm{y}$ otras pienso lo que digo.

Ligeramente expresa luego-el regocijo que le inspira la aceptada versatilidad de las formas, porque ella le permite negligir el menudo rigor de lós eriticos y ajustar su inspiración a la turbia simpleza del asunto :

Unas veces hago décimas otras formo redondillas, otras compongo quintillas aunque salgan todas pésimas.

Y si me pone en apuro el maldito consonante, me agarro del asonante que es más fácil y seguro.

Procedo, pues, en resumen, como mejor se me antoja, $\mathrm{y}$ entre tira $\mathrm{y}$ entre afloja conservo siempre el cacumen. 
Y si esto no sabe bien

200

al criticón que me observa,

que Dios lo guarde en conserva

para siempre jamás, amén.

Y piensa que así se aproxima a la comprensión del más rústico gañán, para mofa de su impertinente adversario :

Que este sea o no poema,

a mí me importa tres rábanos,

ni que me piquen los tábanos

hasta hacerme una apostema.

Que lo lean es mi tema,

sin engañifa ni trampa,

el que maneja una lampa,

el que varea tocuyo,

el que vive allá por Suyo

40

y el que duerme acá en la pampa.

La eufórica adhesión a la libertad romántica no convierte a Manuel Ascensio Segura en un corifeo de la escuela, pues ella envuelve una irónica discusión de su calidad estética. Si bien la "variedad de formas indica [en La Peli-Muertada] la ruptura de la rigidez retórica, inerme antedel avance de la libertad poética proclamada a todo pulmón por los románticos" - según observa Luis Alberto Sánchez (1)-, debe entenderse que ella es sólo unu manifestación de la perplejidad que al insigne criollista infunde el aparente olvido de la mesura clásica, y de sus proyecciones sobre el equilibrio del razonamiento, la discreción sentimental y la dignidad del estilo. Es un clasicista, a quien desconciertan los desbordamientos de la nueva escuela, porque los cree debidos a una irrespetuosa actitud ante los valores consagrados.

Vemos, por ejemplo, que Manuel Ascensio Segura califica su poema como "epopeya de última moda"; y recordamos que, según Aristóteles, se ajustan a la poesía épica los "versos heroicos y yámbicos". Los primeros convienen a los asuntos serios y de excepcional grandeza; y los segundos armonizan con lo burlesco, 216.

(1) Cf. La Literatura Peruana: Tomo V (Buenos Aires, 1951), p. 
pues la monótona facilidad de su ritmo le parece adecuada al lenguaje de los sátiros y de las charlas familiares. En la poesía española, los versos heroicos han sido, tradicionalmente, los endecasílabos, agrupados en sonoras octavas (2); y el metro empleado en La Pell-Muertada es el octosílabo, porque la retórica del idioma lo considera el más sencillo. Lo es también para el propio autor, pues sólo abandona esa medida al interpolar una alabanza al presidente don Ramón Castilla, compuesta en cuartetos dodecasílabos - canto XI- para denotar su seriedad. Y, si el octosílabo suele caracterizarse por su fácil fluidez, debe advertirse la maestría que Manuel Ascensio Segura denota al aprovechar sus posibilidades rítmicas y estróficas. Se aproxima al yámbico o trocaico, si la brevedad de las palabras lo permite:

Que este sea o no poema a mí me importa tres rábanos, ni que me piquen los tábanos hasta hacerme una apostema.

$O$ incide en el ternario dactílico (canto VII). O prefiere alguna de las formas que el cuaternario franquea y mejor se adaptan a la naturaleza del octosílabo español :

\section{Rebozando placenteros tras} en Jideas seductorasli Converso" los patriotas verdaderos, cortas les eran las horas para hacer planes certeros de reformas y mejoras...

Pero siempre denota esta dúctil versatilidad que mayor relieve otorga a la sátira. Y se hallará otra evidente manifestación de las afinidades clasicistas del poeta, si se atiende a la coincidencia entre esas variaciones de ritmos y las transiciones temáticas.

Esos fáciles versos aparecen libremente combinados en diversas estrofas y en romance, permitiendo determinar las fases de la

(2) Francisco Martínez de la Rosa excluye de la epopeya los versos de arte menor, "como faltos de la competente pausa y dignidad"; y aconseja limitarse en esa especie poética a los endecasílabos, preferentemente combinados en octavas, porque éstas son graves y rotundas. 
creación poética. Cuidadosamente ceñido a la retórica tradicional en sus cantos iniciales, Manuel Ascensio Segura adopta luego las variantes que en la rima de las estrofas le convienen, y finalmente apela al cómodo asonante, denotando cierto decrecimiento de su propio interés en el personaje que lo inspiraba, o la urgencia con que se requerían las inserciones parciales en las columnas de El Moscón, o la personal reacción ante los comentarios que provocaron en sus días los hechos del zarandeado Peli-Muerto. En los dos primeros cantos se halla décimas, ortodojamente compuestas; redondillas en los cantos III y IV; octavillas reales en los dos siguientes, pero con una alteración de la rima tradicional en el sexto canto, pues los seis primeros versos de cada estrofa no la llevan alternada; sextillas esdrújulas -compuestas como agrupación de una redondilla y un pareado- en el séptimo canto, y graves en el octavo; quintillas en los cantos noveno y décimo; octavillas italianas, cuyos versos primero y quinto riman entre sí o van libres, en los cantos undécimo y duodécimo, respectivamente; y romance desde el canto décimo tercero, con asonancia en E-O, E-A, A-A y A-O sucesivamente. De manera que el poeta ha ajustado su obra a una metódica variación de las combinaciones estróficas, y sólo abandona tal propósito cuando juzga conveniente precipitar la relación de los hechos.

En el plaßinicial de da "epopeya" se advierte que cada una de las formas mencionadas corresponde a un capítulo de la vida del protagonista; y son dos los cantos donde aparecen, porque uno está destinado a las reflexiones pertinentes. Así conviene a la estructura que la retórica del clasicismo fija a la poesía épica y a la sátira, en las cuales se debe intercalar episodios que aún indirectamente coadyuven a esclarecer el asunto principal o dejar puntualizadas las enseñanzas morales que la burla sugiera. El primer canto desenvuelve una humorística invocación a las musas, y ensaya el tono general del poema; el segundo canto refiere el nacimiento de Peli-Muerto; el tercero es una justificación de la actitud poética del autor, y el cuarto, un relato de la infancia de PeliMuerto; el quinto censura a quienes hacen exhibición de su patriotismo para ocultar las ansias de provecho personal, y el sexto enuncia cómo empezaron a manifestarse las habilidades de PeliMuerto; el séptimo es un interludio en el cual se plantean sumariamente los términos del debate que sostenían el poeta y su vilipendiado adversario, y el octavo recuerda las veleidades de Peli- 
Muerto en los tormentosos años de la Confederación Peruano-Boliviana y la anarquía militar; el noveno defiende la idea de que todos los hombres son iguales por su naturaleza y sólo se les debe diferenciar en atención a su virtud, y el décimo da cuenta de las circunstancias que determinaron a Peli-Muerto para quebrantar su adhesión al Directorio y plegarse a la revolución constitucional. Es claro, pues, que el plan de La Peli-Muertada fué trazado con el propósito de ceñirse a las formas clásicas, y aquellas reflexiones interpoladas en el desarrollo del argumento asumen una significación equivalente a la que desempeñan los episodios en la epopeya. Pero así se prolongaba con exceso al poema, y, aunque las peripecias del protagonista eran expuestas con malicia y gracejo, parecían circunstancial ilustración de los conceptos morales antepuestos a cada aventura. De allí que las reflexiones sean limitadas sólo a tres octavillas en los cantos XI y XII, y eliminadas cuando el poeta desea aligerar y simplificar la relación de los hechos. Y como esto coincide con la adopción del romance, es lógico deducir que tal metro le parece heterodojo en la epopeya, y lo destina a expresar el abandono del plan y la incidencia en una tónica sencilla.

La Peli-Muertada se ajusta a la primera de las modalidades que Aristóteles distinguió en la poesía épica, en cuanto el personaje y sus hechos corresponden precisamente auna historia de la vida cotidiana. Y Jomo éstaces presentada en su propio tiempo, refiérense a ella "cuantas cosas entonces sucedieron a uno, o a muchos, sin otra conexión entre sí más de la que les deparó la fortuna". También se ajusta a la exigencia que Horacio impone a la poesía satírica, al establecer que "convendrá mezclar [en ella] lo serio con lo jocoso en forma tal, que nunca dios ninguno - ningún héroe que vió antes el público en medio de oros y de regia púrpura, descienda por su lenguaje vil a las lóbregas tabernas, y que tampoco mientras huye del suelo se remonte hinchado hasta las nubes". Y aunque alterna la burla con los juicios que los hechos sugieren, no llega a "remozarse con versos demasiado tiernos, ni avillanarse con soeces expresiones propias de quien nació en las encrucijadas". Se ajusta a la escrupulosa opinión de Francisco Martínez de la Rosa, en cuanto advierte que la acción de la epopeya no debe ser "tan ilimitada que llegue a agotar el sufrimiento de los lectores"; que en ella "debe haber un personaje principal que ocupe el primer término y sobresalga 
entre todas las figuras", como una "especie de centro" que contribuya "a denotar la unidad de acción", y que, aun careciendo de grandeza la acción y el personaje, por haber emergido de una tradición reciente, y por la naturaleza que la sátira les atribuye, los contornos de sus enseñanzas privan a uno y otra de su posible odiosidad. Y también se ajusta a la cortesana pulcritud de Boileau, cuya preferencia por la poesía épica se arraiga a la donosura y la pompa que le otorga lo maravilloso, pues

Sans tous ces ornements le vers tombe en langueur la poésie est morte ou rampe sans vigueur; le poête n'est plus qu'un orateur timide, qu'un froid historien d'une fable insipide.

En consecuencia, aconseja:

Soyez vif et pressé dans vos narrations; soyez riche et pompeux dans vos descriptions. C'est la qu'il faut des vers étaler l'élégance; n'y présentez jamais de basse circonstance.

$Y$, asociándose al pensamiento de todos los preceptistas clásicos, estima que la inspiración debe ser auxiliada por el estudio:

Mais souven parmi noús umpoêteosans art, qu'un beau feu quelquefois échauffa par hasard, enflant d'un vain orgueil son esprit chimérique, fiêrement prend en main la trompette hérol̈que: sa muse déréglée, en ses vers vagabonds, ne s'eleve jamais que par sauts et par bonds: et son feu, depourvu de sens et de lecture, s'éteint a chaque pas faute de nourriture.

De manera que Manuel Ascencio Segura ha seguido escrupulosamente las exigencias retóricas, al determinar la acción y el carácter del personaje central, el plan y el metro, el tono y el estilo de su poema. Si apela a la libertad romántica, es sólo para embozar la íntima renuncia que le infunde el rebajar la majestad de la poesía al emplear su divino lenguaje en la glosa de oscuras picardías. Si aparenta echar al olvido las enseñanzas de los retores famosos, expresa una táctica defensa de su personal adhe- 
sión al clacisismo. Y tanto su personalidad como su obra lucen contornos que no se advierten debidamente a través de la exclusiva atención a sus piezas dramáticas, pues el criollismo muestrase sólo anecdótico y no esencial, y, en cambio, asoma una sólida convicción humanista, expresada castizamente.

Peli-Muerto -a quien también se conoció en su tiempo como Ambidextro, El Legista, Pancho Sácate la Mecha, Negro Pancho, Talega de Amores, Gallinazo y Mate Quiñado- es un personaje novelable, ya se le considere como tipo humano, ya como fruto de las turbulencias engendradas por el caudillaje militar. La sátira, que deforma y exagera sus caracteres fundamentales, da a su silueta unos contornos carentes de todo matiz apacible, y denuncia la pasión del poeta que la ha trazado. Faltan en ella los contrastes del claroscuro, los niveles del bajo relieve, los ángulos de una correcta perspectiva. $Y$, no obstante la veracidad de los rasgos, la pintura lograda parece irreal: pues, si bien pone en evidencia su actitud reptante, su absoluta falta de moral, y su parasitismo inescruploso, es lamentable su carácter episódico y estrictamente individual. No ha querido ver el poeta la calidad genérica de su personaje, ni ha querido asignarle la significación que al servirle de fondo le confieren su sociedad y su época. Derrochando su ingenio para vivir a costa del esfuerzo y los bienes ajenos, su figura podría ser entroncada a la picaresca española, pero su actividad de cambiabanderas y turiferario, su afectación política y su ambición mal sostenida, le otorgan una condición mucho más compleja. Petulante y atrevido, indiscreto y desvergonzado, calumniador e intrigante, Peli-Muerto encarna la negación de las jerarquías y un reto permanente a las convenciones establecidas. Cada una de sus aventuras denuncia una improvisación, y toda su existencia ignora la renovada inminencia y la perennidad del destino.

Nación una noche, ante los adustos muros de la secular fortaleza que guarnece la rada chalaca, y bajo la pálida luz de la luna. A la mañana sigutente se agolpaban los curiosos en torno a la dolida madre y el prieto mulatillo que lloraba en su regazo; $\mathrm{y}$, sorpresivamente reconocida aquella como la mujer de un $p e$. nado a quien la guardia conducía a efectuar su trabajo cotidiano, fué internada a la fortaleza con el chicuelo. Creció éste entre 
los rudos y maldicientes presidiarios, a la ventura y desarrapado, aprendiendo las artimañas que en sus tertulias referían aquellos o ejecutando en el vecino poblado las comisiones que le encargaban. Pero al fin cumplió el padre su condena, y la familia trasladóse a Lima, donde aquel alternó primero el pillaje con e! cargo de sereno, y, para despistar a la justicia, pasó luego a ser yerbatero. Campante y avizor, lo acompañaba siempre el pequeño Pancho, con la misión de otear los peligros y trasmitirle los avisos pertinentes; y tan aprovechado salió a la postre, que por sí solo acometía algunas empresas; pero la continuada impunidad lo indujo a subestimar las precauciones, y cierto día fué sorprendido cuando escondía entre la yerba unos objetos ajenos. Padre e hijo, corridos, no pararon hasta Huacho. $Y$ ambos entraron al servicio de un escribano, que así fraguaba escrituras como adiestraba testigos falsos, y solía remunerar a sus amanuenses con alguna largueza. No obstante, el reducido escenario de aquel lugar campestre, y la vida sedentaria, no agradaron a Pancho, quien una noche birló al actuario su dinero y objetos varios, y nuevamente volvió a sentar sus reales en Lima y Callao. En tanto, su padre, tan defraudado como la víctima del hurto, incorporóse a una partida de montoneros para medrar a la sombra de las contiendas civiles, y desde entonces ninguna lengua dió ya noticia de sus hechos.

Emancipada der ga Putelai paternap Pancho ıvivió desaprensivamente, y tan pronto disfrutó de alguna bonanza como sufrió la inopia. Empleóse al servicio de un juez venal, y a su lado cometió una fechoría en perjuicio de unos soldados, que le impusieron vejatoria azotaína. Un tiempo anduvo solicitando pequeños préstamos, que jamás pagaba. Y con la misma ansia que el náufrago a un madero, asióse a la perspectiva que le brindó la Confederación Peruano-Boliviana, pues su violencia determinó la ampliación de la vigilancia sobre los elementos opositores, y para hacer méritos prestóse a ser confidente. Fué premiado con un empleo subalterno en la administración del Estado, y sugestionóse a tal punto con esa posición que se fingió cortesano y halagador, ofreciéndose a cuantos visitaban la oficina e importunando a las damas con sus galanterías y solicitudes. Quiso un día arrebatci las caricias de una rústica morena, que echó voces airadas co:: tra el descomedido galán, y a ellas acudieron cuantos se hallaban en las estancias vecinas, que condenaron la audacia y deci- 
dieron que el agravio debía ser reparado con el matrimonio. Pancho no había calculado esta coyuntura, porque en su habitación no tenía ni una mala silla, y tantos habían sido sus engaños que resultábale azaroso pensar en desplegarlos nuevamente; pero se dió maña para trasladar a su casa algunos muebles de la oficina, y cuando esto fué advertido perdió el empleo. Desde entonces engrosó la legión de los quejosos, y pudo alegar algún título para solicitar su reposición, al terminar la Confederación en la batalla de Yungay. Su esperanza le permitió obtener algún crédito y contraer deudas, pero pasaron los años de la Restauración y sólo accedió a sus peticiones el general Juan Crisóstomo Torrico. Mudable como siempre, la fortuna le fué muy pronto esquiva, pues a este caudillo lo desplazó del poder el general Francisco Vidal, y sus actos quedaron anulados. Por eso recibió Pancho con alborozo el cambio que puso término al flamante gobierno; por calles y plazas saludó como salvador al general Manuel Ignacio Vivanco; y recuperó su empleo. De nuevo la fortuna mostrósele inestable, cuando en el sur empezó a flamear la bandera de la restauración constitucional; empezó a murmurar públicamente contra el gobierno, y para evitar que el desacato cundiera dictóse auto de prisión contra él; pero ya el atrevido había buscado su salvación en la distancia, y sobre una yegua robada traspuso los Andes para presentarse al general Ramón Castilla e impresionar a sus parciales con la responsabilidad que le cabía en una presunta conspiarción rcontral la ividd idel Supremo Director. Fué nombrado comisario de guerra; y durante los meses que desempeñó tal cargo, en las confusas circunstancias de la revolución, es claro que se ingenió para roer los caudales que pasaban por su mano y acumular una respetable cantidad.

Terminada la guerra civil, Pancho se instaló en Lima con lujo ostentoso, y dió en el extraño capricho de cubrir su confusa pelambre con una peluca rubia y lacia. Con unónime sorna fué aplaudido por el público, cuando se presentó así en el teatro, y la prensa aplicóle el certero remoquete de Peli-Muerto. Pero, lejos de sobrecogerse ante la burla, agregó a su modesto patronímico un sonoro apellido, y con arrogancia vistió los oropeles de un uniforme convencional; afectó tener ascendiente en los altos círculos del gobierno, y conoció la adulación; frecuentó salones, alternó en conversaciones doctas, derrochó dinero en el juego, y galanteó lindas mujeres. Exhausto quedó su caudal, a consecuencia de tan- 
ta imprevisión, y volvió a frecuentar la aventura y la trampa. Sufrió desaires e improperios, los acreedores le vocearon sus exigencias en plena calle, y hasta en la prensa relucieron quejas y denuncias contra él. Buscó entonces el benévolo amparo de un jefe militar, a quien el gobierno había nombrado gobernador de la provincia litoral de Piura; angustiosametne le solicitó que propusiese su nombramiento como secretario, $\mathrm{y}$, sin aguardar la respuesta oficial a esta instancia, embarcóse precipitadamente hacia dicho lugar.

Para hacer verosímil su presentación como un valido del gobierno, y sobrellevar su falta de recursos, Peli-Muerto instalóse en la propia casa de la autoridad provincial, con un primo suyo $\mathrm{c}$ quien hacía fungir de criado; y su involuntario huésped hubo de tolerarlo, porque juzgó que el escándalo rebajaría su ascendiente ante la opinión de los piuranos. Por añadidura, holgóse en aquella ciudad con una prima, a la cual alimentaba con la comida que su criado sustraía en la cocina de su tolerante protector e inició una sorda guerra contra Manuel Áscensio Segura, que a la sazón ocupaba la ambicionada secretaría. Y el mismo personero gubernativo, que a regañadientes sufriera las tretas de Peli-Muerto, creyó a la postre sus infundios: porque hubo de viajar a $\mathrm{Li}$ ma para dar cuenta de la forma como había hecho cumplir una resolución y, al volver, se le hizo concebir que el secretario minaba su prestigio. La coyuntura política favoreció quizá esta especie, pues las faccionges adjatábanse en una contienda electoral cu-ya violencia no tenía precedentes, y Manuel Ascensio Segura pudo ser afectado por alguna oscura maniobra. Pero el integrante no obtuvo el codiciado empleo, y enderezó sus aspiraciones hacia la capitanía del puerto de Paita, que le fué concedida tras reiteradas y diversas peticiones, y en cuyo desempeño renovó sus usuales picardías. Depuesto al fin, volvió a Piura; y otra vez emprendió campaña pública y privada contra Manuel Asscensio Segura, restablecido en la secretaría y a quien Peli-Muerto atribuyó su desgracia. Pero ya no se le dió crédito; y, no obstante su renuencia, hubo de acatar la orden por la cual dispuso el gobierno que se trasladase a Lima, pues muy bien se conocía su mala gestión en la capitanía y los peligros que sobre la tranquilidad de la provincia cernian sus amaños e insidias. 
¿Quién fué Peli-Muerio? Pues, según anuncia Ricardo Palma, quien debió conocer su estampa física y sin duda escuchó a Manuel Ascensio Segura la versión oral de las tropelías que cometiera, ese personaje fué una "entidad política de aquellos tiempos". Es claro que muy discretamente soslaya así su identificación, y aún permite el tradicionista que se le atribuyan carácter y magnitud muy diferentes a cuanto de él se dice en La Peli Muertada. Por añadidura, induce a un prudente juzgamiento de los trazos con que el poeta bosqueja su condición moral y su peripecia biográfica, al advertir que en el fondo alientan "las polémicas de partido" y las pasiones personales. De manera que hemos de considerar la realidad humana de Peli-Muerto como una incógnita, creada con la delectación que motivaron el recuerdo y la burla de sus desventuradas aventuras, y mantenida por los coetáneos para no dar permanencia a las rencillas que sus hechos movieron. Y, si bien acucia hoy nuestra curiosidad, esa in cógnita se reviste con la prestancia que da figuración a los tipos sociales o literarios y difícilmente acompaña a las caricaturas individuales.

Ya apuntó Luis Alberto Sánchez que "podría enfrentarse el niño Goyito, prototipo del engreído limeño, con Peli-Muerto, representante del expósito arribista y descastado" (3). Y, así como se ha celebrado el acierto que Felipe Pardo logró al concebir aquel retrato del viajero cincuentón y timorato, sin que a nadie importe la posibiliaad de encaimarlo en um sujeto determinado, muy bien podría prescindirse de todo reto a la oscuridad que encubre los contornos del mulato inescrupuloso y si-

(3) Obra citada : Tomo V, p. 139.

La comparación entre el niño Goyito y Peli-Muerto fué anteriormente desenvuelta, con mayor detalle, por Luis Alberto Sánchez. En La Literatura del Perú Republicano - Derrotero para una historia espiritual del Perú (Santiago de Chile, Editorial Nascimento. 1936), dice:

"El niño Goyito es el símbolo del limeño adinerado, engreído por las tías viejas; es el mocito sociable y comodón, cuyo viaje constituye piedra angular en el calendario de la familia. Peli-Muerto es el expósito feo, desdeñado, ante quien se detienen la atención de un sargento, de una vieja, de un pelafustán y de un poeta tuerto. El niño Goyito sólo pertenece a Lima, pero Peli-Muerto, de puro local, es un expósito que lo mismo puede ser mosca huérfana de La Mosquea, gato expósito de La Gatomaquia, rana abandonada en La Batracomiomaquia". 
mulador. Pero las circunstancias que el poeta detalla constituyen una tentadora invitación a sondear en la personalidad y la vida, para agregar los matices que desdeñó Manuel Ascensio Segura. A ella ha respondido Luis Alberto Sánchez, al forjar la versión de una rivalidad entre las dos figuras representativas del criollismo, a base del temor a "la gents pardusca", vencido por el poeta en el trance germinal de su creación: porque en esa gente ve aludidos a "los que se arremolinan en torno a Pardo y Aliaga" (4), y le basta atender a sus implicancias para deducir que tal término "revela contra quién se dirigía" (5) La Peli-Muertada. Por añadidura, subraya la significación de algunas alusiones enderezadas contra su antagonista, porque presumía ser "diplomático y político", y parecía estar "maniático por hacerse poeta lírico"; y opina que Manuel Ascensio Segura pudo referirse al travieso letrillero, valdado entonces por la parálisis e inclinado a expresar sus cuitas en depurados versos. Pero, no obstante la sugestión de las coincidencias enunciadas, es fácil advertir que la "epopeya" menciona circunstancias de una rivalidad local y aún giros de un debate público, y que nada de ello conviene a la conducta y el lenguaje de Felipe Pardo y Aliaga. Por ejemplo:

Llámeme en buena hora zángano, y tuerto $y$ yruto $y$ rovíparo; yo le digo que es un pícaro, un asqueroso carángano, que se puede sin obstáculo botarlo en un receptáculo.

Y que hombre tan poco sólido, - más bien un catecúmeno, retoño de un energúmeno, lleno de infamia y estólido, que un hombre que todo es cábulas no puede hablar sin fábulas .

O recuérdese que Peli-Muerto editó en Piura La Tarántula, para denostar contra el bizarro costumbrista, y obsecuentemente ofrecía ejemplares a quienes encontraba en las calles:

(4) Cf. La literatura del Perú (Buenos Aires, 1939), p. 97.

(5) Cf. La Literatura Peruana: Tomo V, p. 122. 
Allí está, si no, el periódico

de las inflamables líneas

y de las materias ígneas,

que hasta al lector más fosfórico

le causan sueño sus fárragos

tan enjutos como espárragos.

Pues solo el autor magnífico

que ha hecho sus tripas termómetro

y quien sabe si barómetro

$\mathrm{u}$ otro instrumento científico,

puede sin darle parálisis

hacer con calma su análisis.

O atiéndase a la implícita calificación del rival como sujeto petulante y lenguaraz:

\section{Y supuesto que de mí émulo}

se da jactancioso el título,

en el próximo capítulo.

lo haré ver con menos máscara,

quitándole más la cáscara.

La verdad es que, guiado por sus afinidades éticas y psicológicas, Manuel Ascensio Segura sólo fué adicto a la expresión objetiva y directa, e ignoró lás ofensivas remotas que tan Gratas son a los jugadores de ajedrez.

De otra parte, el propio Luis Alberto Sánchez hace ostensible su perplejidad ante la incógnita, y demuestra cuán insostenible es la hipótesis expuesta, en tanto que sugiere tres posibilidades diversas. Leemos (6):

...conviene descubrir en el poema la identidad de Peli-Muerto, a quien Segura pinta con lujo de detalles. A simple vista, ocurre pensar que él pudo ser o el síndico de Catacaos, don José Dionisio Sánchez, o el abogado de éste, don Manuel León Alva. Pero otros datos llevan a suponer que se trata de un prohombre de la época, valido de varios gobiernos y notorio por sus malos manejos.

(6) Cf. El Señor Segura, Hombre de Teatro (Lima, 1947), p. 100. 
Haría falta averiguar si José Dionisio Sánchez había nacido en el Callao, y si se cumplen en él todas las condiciones que el poeta asigna a su detractado PeliMuerto. A más, de acuerdo con el poema todo... PeliMuerto era mulato o mulatoide.

Y, hostigado por el deseo de hallar solución al problema apunta (7):

Cuando Palma cree que en La Peli-Muertada malgasta Segura su ingenio, parece como que olvidase la finura de muchas de sus estrofas, su contagiosa alegría y también el motivo sarcástico, probablemente contra un señor Paz Soldán, según entiendo, que inspira la obra.

Pero estas sugerencias tampoco se ajustan a las noticias que acerca de Peli-Muerto ofrece Manuel Ascensio Segura: pues, de haber sido síndico de Catacaos, no sería posible identificarlo como forastero en la región; la calidad de autodidacto no corresponde a un abogado; y en Piura no se halla por esos años ningún dato que corrobore la estancia de algún "señor Paz Soldán". De manera que la incógnita subsiste, y cabe plantear nuevamente la pregunta: ¿Quién fué Peli-Mureto?

De todos los datos que la "epopeya de última moda" consigna, sólo har dos susceptibles del ser utilizados como los indicios básicos de una jnvestigación Fl Frimero es ngada menos que el nombre civil de Peli-Muerto: Pancho, que a título amistoso o despectivo se trocaba en Negro Pancho, y nos permite deducir que en el bautismo se le llamó Francisco ( 8 ). Y el segundo se halla

(7) Cf. La Literatura Peruana : Tomo V, p. 135.

(8) A base de este nombre juzgué que Peli-Muerto podía ser Francisco García, designado -en febrero de 1849 - para reemplazar a $\mathrm{Ma}$ nuel Ascensio Segura en la secretaría de la gobernación de Piura; y trasladado, en octubre del mismo año, a igual cargo en la gobernación de Junín, en tanto que Manuel Ascensio Segura retornaba a la provincia norteña. Pero la identificación no es muy cabal, porque Francisco García fué propuesto por el coronel José Noriega, gobernador de Piura, para actuar la matrícula de contribuyentes, y la honestidad que esta misión supone, no armoniza con la triste fama de Peli-Muerto; porque éste fué destinado a la capitanía del puerto de Paita y no al empleo de Manuel Ascensio Segura; y porque Peli-Muerto mantenía su guerra contra el celebrado costumbrista, aun en 1851 . 
en la circunstancia de haber sido destinado a la capitanía del puerto de Paita, en 1849, mientras Manuel Ascensio Segura desempeñaba una oficialía en el Ministerio de Gobierno. Pero las publicaciones oficiales de la época no insertan la resolución pertinente, y el aciago sino de nuestros archivos no permite hallar la información requerida. Quizá es mejor así. La renuncia a una exigencia erudita no empece a la justa estimación de la obra creadora, y mantiene la sugestión que la incógnita brinda a cuantos buscan en los tipos litararios la representación y el encanto de un carácter. Que viva Peli-Muerto, el mulato petulante y simulador, arribista e inescrupuloso, cambiabanderas y turiferario, hijo de una democracia ingenua y turbulenta.
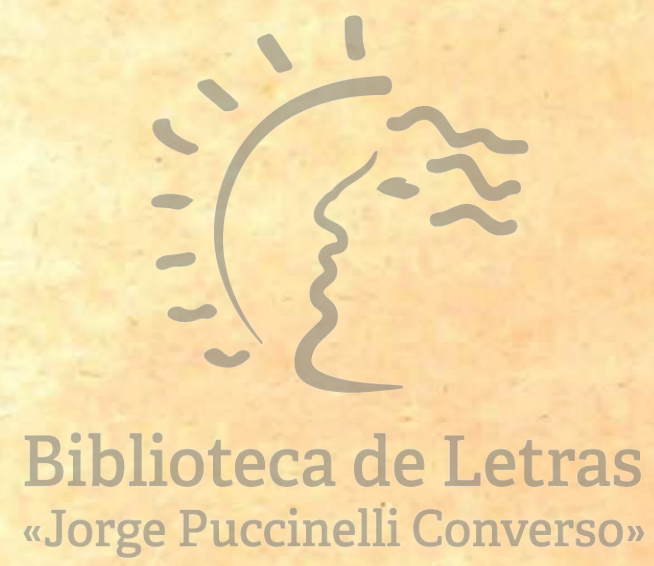